ror on account of the suffering which they undergo whenever coitus is attempted. These patients are, of course, greatly relieved by the removal of those organs which have caused their suffering. Sometimes in such cases as these the sexual desire is greatly increased after an operation and this increase may continue for years.

In some women with a pronounced neurotic history there appears to develop after operations on the pelvic organs a periodical mania in which sexual fury is the pronounced symptom. In such cases there are periods in which the woman indulges in sexual excesses for days at a time, going clandestinely to houses of easy virtue for the purpose; and then there follows a period in which (very often of several weeks' duration) there is little or no sexual desire at all for them, to be followed in its turn by another period of sexual fury. These are cases of recurrent sexual mania, akin to recurrent attacks of dipsomania.

I would say this: that there is little doubt that the removal of the pelvic organs is very prone to induce degenerative cerebral changes in those who are predisposed by heredity to a neurosis. In other words, you take a woman who has a tendency to nervous disease in the family, and who is nervous herself, and that operation may induce paranoia, which might not have developed until the natural menopause at the age of fifty, or might not develop at all.

Reflexes.-In regard to the pain in the back, you can account for that by pressure on the nerve centers in the pelvis.

Constipation.-Simply in those cases where neurasthenia is produced.

Typical Symptoms of Neurasthenia Resulting from this Operation 'in the Case of a Patient.-Walks with difficulty on account of weakness and pain, the pain being located in both thighs. She has vertigo, insomnia, disagreeable dreams, depression of spirits, crying attacks, irritable, fretful and a feeling of pressure in the head, and headache; flatulency, dyspepsia and constipation. Now, these are typical symptoms. In a good many neurasthenic subjects there is a great degeneracy of mind because they think that people can tell they have had this operation done by looking at them, and they get depressed from that, avoid society and hate to go out. I have seen a number of such cases.

When we remove the testicles from the male, he becomes timid and loses his virility and courage; he becomes fat and gross; there is also a similar change in the animal. The horse has not the health, the virility or the courage of the stallion. Now, simply cutting off his toe would not make this change. There is something vital taken away from him, and the parts taken out constitute something that he especially requires.

With regard to hysterectomy, it is well-known that a woman on whom hysterectomy has been performed loses her sexual desire in about eighteen months therefrom, barring cases $I$ have already mentioned. If it is possible to save the uterus, why not do it? If it is possible to save only half an ovary, save it. If it is possible to save only part of a tube, save it, provided that it is, or can be made, patent. If there is a fibroid in the uterus, remove the fibroid and leave the uterus, in selected cases. If there is a cyst in the ovary, remove the cyst and leave what healthy ovarian tissue you can. You know that this work can be done and that the resected ovary or tube will heal. If there is mild oozing of blood, the pelvic peritoneum will take care of it. This is conservative surgery. May it continue to develop in the future!
BIBLIOGRAFHT.

Beashan, A. L., The Jounnal A. M. A., 1900, $x \times x y, 539$

Burrage, W. L., Amer. Jour. Obstet., 1900, xli1, 195.

Harris, P. A., Ann. Gyn. and Ped., 1900, xiii, 752 .

Dudley, Amer. Jour. Obstet., 1900, xlili, 397.

Jayle, Clinique (Montreal), 1900 , vi, 286.

Kelly, J. K. Glasgow Med. Jour., 1900 , lii, 115

Massey, C. G., Amer. Gyn. and obstet. Jour., 1900, xvi, 116.

Jayle, Presse Medical, $1900,133$.

Vidal, Revue de Gynecologies (Paris), 1900, iv, 81

Jarsallon, L., Lyon Medicale, 1899-1900.

Goldspohn, Trans. Amer. Assoc. Obstet. and Gyn., 1898, 307-315.

Goldspohn, Trans. Amer. Assoc. Obstet. and Gyn., 1898, 307; also

Amer. Gyn. and obstet. Jour., 1899, xiv, 1-6.

Coe, H. C., Trans. Amer. Gyn. Soc., 1898, $x \times 111,381,95$.

Palmer, C. D. Cin. Lancet-Clinic, 1899. n. s., xlii, 1.

Carstens, J. H., Internat. Clinics, 1898, 8 s. iii, 283.

M03, $1897-18908$.

Wiener, J., N. Y. Med. Jour., 1897, IXv, 853-57.

Champneys and Robinson, Practitioner, 1897, 1viii, 641-654.

Jayle, Revne de Gyn. et de Chirur., 1897, 1, 403-456.

Polk, W. M., Amer. Gyn. and Obstet., 1897, xi, 267.

Stinson. J. C. Occ

Pozzi, Paris, 1897. Mirror, 1898, ix, 55.

Knauer, Centralbi. f. Gyn., 1898, xxi1, 201, 1896-7.

Halley, Kansas City Med.' Record, 1896, xiii, 73.

Cragin, E. B., Med. News, 1896, Ixviii, 719

Thomas, Medical Record, 1896, 1,769 .

Coe, H. C. N. Y. Poly., 1896, viii, 107

Clark, J. G., Thera. Gaz., 1896, 3 s., xii, 802

Polk, W. M., 'Trans. Amer. Gyn. Soc., 1896, xxi, 3.

Porter, M. F Amer. Jour. Surg. and Gyn. 1896, viii, 164

Fish, E. F., Milwaukee Med. Jour., 1896, iv, 370.

Lee, E. W., Omaha Clinic, 1896, ix, 98 .

Dunn, B. S. South Calfornia Practitioner, 1896, xi, 455.

Montgomery, E. E., Med. Council, 1897, 1i, 5 .

Johnson, J. T., Amer. Jour. Gyn, and Obstet., 1899, xiv, 1.

Johnson, J. T., Amer. Jour. Gyn, and Mobstet., 1899.

Johnston, Geo. Benn., Med. News, May

Glass, J. H., Med. News. April 29, 1899.1898.

Kelly, H. A., Brit. Med. Jour., Jan. 26, 1898. 1897 , xi, p. 502. Madden, T. M.. Amer. Gyn. and Obstet. Jour., 1897 , Xi, $p$.

Polk, WV. M., N. Y. Jour. Gyn. and Obstet., 1893, ili, p. 649; also Amer. Jour. of obstet., xxiv, $9,1891,1050 ;$ also $\Delta$ mer. Jour. of Amer. Jour. of Obstet., xxiv, 9, 1891, $1050 ;$;

Obstet., 1887, xx, 630; Jour. of Obstet., 1896. Munde, P. F.,

Gordon, Amer. Gyn. Soc. and Amer. Med. Asso. and Me. Med. Asso.

Doleris, Amer. Jour. Obstet., 1890, xxili, 1009 ; Dudiey. 1336 ; Martin, 800; Landau, 1157; Polk, 1375; Mitchell, 555.

Polk, Amer. Jour. Obstet., 1891. xxiv, 1039.

Doleris, Amer. Jour. Obstet., 1892 , xxv, 130

Polk. Amer. Jour. Obstet., 1893, xxvil, 883.

Barrows, Amer. Jour. Obstet., 1893 , xxviii, 804 ; Pozzi, 446.

Apostoli, Amer. Jour. Obstet., $1894, \times x \times, 775$; Vulliet, 285 :

Dudley, 129 ; Delangre, 455; Glasgow, 705-747.

Praeger. Amer. Jour. of Obstet., 1895, xxxii, 891

Dunn, Amer. Jour. Obstet., $1895, \times x \times v i, 571 ;$ Robb, 289

Dudley, Amer. Jour. Obstet., $189 \overline{5}$, xxxvil, 214 ; Russell, 293

Dudley, Amer. Jour, Obstet., 1895, Xxxvili, 407.

Lucas, Amer Jour Obstet., 1899, xxxix, 115; Johnson, 221.

Lucas, Amer. Jour. Obstet., 1899, xxxix, 115

Dudley, Amer. Jour. Obstet., 1900, xlii, 397 ; Montana, 268;

Burrage, $42,90,195$

Morris. Amer. Jour. Obstet., 1901, xliii, 582 ; Vidal, 267; Mau laire, 266 .

Beyea, Amer. Jour. Obstet., 1901, xliv, 324-374; Dudley, 417.

Burrage. W. L., Med. News, April 13, 1902 .

Goldspohn, A.,"Trans. Amer. Asso. of Obstet. and Gynecologists. 1901,230

Beyea, H. D., Amer. Jour. of Obstet., September, 1902

Harris, P. A., Med. News, Oct. 27, 1900.

\section{THE CAPACITY OF A HUMAN MUSCLE FOR WORK.*}

JFSSE GWORGE HOLMES, From the Physiologic Laboratory of Northwestern University
Medical School. CHYCAGo.

HISTORICAL REVIEW.

Each year adds its share to the work that is being done by the different investigators in the study of muscular contractions, neuromuscular fatigue and the ability of a muscle to do work. To Mosso ${ }^{1}$ must be given the credit of first making investigations with the human muscle. The instrument used by him in his work consisted in a weight and pulley. The muscular power obtained he expressed as weight multiplied by the dis-

* Read at the Fifty-fourth Annual Session of the American Medical Association, in the Section on Pathology and Physiology, and approved for publication by the Executive Committee: Drs. . Hektoen, F. B. Wynn and W. S. Hall.

1. Mosso: Ueber die Gesetze der Ermudung, Archives fir Physiologie, 1890 , p. 89. 
tance through which it was raised. Maggiora, ${ }^{2}$ Iombard, ${ }^{3}$ Treves, ${ }^{4}$ Cleghorn and Stewart, ${ }^{5}$ Storey ${ }^{6}$ and others continued investigations, introducing various modifications into the technic, thereby obtaining results of considerable value and interest.

Thus the original idea and the one followed more or less closely since has been to have the muscle raise and lower a weight successively through a given distance. It was found that a muscle can raise the weight at a regular rate until, as fatigue sets in, the height of the contraction becomes less and the movements become slower and more difficult. The amount which a muscle can do depends on the muscle and the technic used, the rapidity with which it contracts and the weight it has to lift. Among the objections that soon became evident are the following: (1) That the muscle after a short time becomes so fatigued that it can no longer lift the given weight. It can still exert a considerable amount of force, and if a lighter weight be used it can lift it. (2) It is found that only isotonic contractions are possible in the use of the weight ergograph, and that the muscle is under a continuous tension. (3) The greatest tension of the muscle is that required to orercome the inertia of the weight in starting it.

Others, thinking that with the use of the weight the muscle does not work to the greatest advantage, employed the spring. Cattell, ${ }^{7}$ Binet and Vaschide, ${ }^{8}$ Franz, ${ }^{9}$ Hough, ${ }^{10}$ Fick $^{11}$ and others have used this form quite extensively, but it has not replaced the use of the weight entirely. The advantages of the spring over the weight are the following: (1) The slightest movement made by the muscle can be recorded, whether it is of the isotonic or isometric form. (2) An interval of rest is allowed the muscle between the periods of relaxation and contraction. (3) The inertia is less pronounced. On the contrary, however, Franz ${ }^{12}$ says that most of the objections which apply to the weight will also apply to the use of the spring. Thus it may be seen that the introduction of the isometric contraction, a condition not possible with the weight, has added interest to the study of action of a muscle.

GENERAL CRITIQUE.

In answer to the objections to the weight or spring ergograph, it has been mentioned that most of them are objections either to the mechanical construction which might easily be overcome, or to their use in particular problems. But no mention was made to the most serious fault of these methods, viz., that the muscle does not work under conditions which are physiologic. With the weight, the muscle is "loaded," having no interval of rest at any time, while with the spring it is "afterloaded." A large part of the energy expended by either the "loaded" or "after-loaded" muscle is not accounted

2. Maggiora: Ueber die Gesetze der Ermudung, Archives für Physiologie, 1890, p. 191.

3. Lombard: Some of the Influences Which Effect the Power of Voluntary Muscular Contraction, Jour. of Physiol., 1892, xiii, p. 1.

4. Treves: Sur les lois du travail musculaire, Archiv ital de Biol., 1898, xxx, p. 1 .

5. Cleghorn and Stewart: Inhibition Time of a Voluntary Muscular Contraction, Amer. Jour. of Physiol., 1901, v.

6. Storey: The Influence of Fatigue on the Contraction of Human Muscle, Amer. Jour. of Physiol., 1903, vili, p. 355.

7. Cattell : Science, N. S., 1897, จ, p. 909.

8. Binet and Vaschide: Annee psychologique, 1898, iv, pp. 245, 253,303 .

9. Franz: Methods of Estimating the Force of Voluntary Contractions and on Fatigue, Amer. Jour. of Physiol., 1901, iv, p. 348.

10. Hough : Ergographic Studies in Neuro-Muscular Fatigue, Amer. Jour. of Physiol., 1901, v, p. 240.

11. Fick: Pfluger's Archiv für Physiologie, vol. xli, p. 176

12. Cf. p. 353 for, because it is expended either in the form of internal energy or as external work which can not be computed. The loaded muscle, on the one hand, becomes tetanized early, and though the weight tends to stretch it during relaxation and thi rest period, the results of such experiments with muscle-nerve preparations of a frog make it evident that the muscle neither relaxes nor rests between contractions after the fatigue sets in. The after-loaded muscle, on the other hand, must be exerting a certain amount of energy in "easing" back the weight to its rest which would otherwise fall back under the influence of gravitation. The cycle of the former is contraction, relaxation with load and stretching. With the latter it is contraction, relaxation with load and rest.

Put in a practical way, the loaded muscle might be explained thus: Let a man lift a twenty-five-kilogram weight from the floor to the table, and without resting it on the table lower it to the floor; but before it touches the floor let him raise it again to the table and repeat until he is exhausted. At no time does he rest from his weight, and fatigue comes on quickly. If, however, in the interval between the lowering and the next lift the weight is allowed to rest on the floor for a few seconds, the muscle will have a chance to recuperate, and he will be able to do more work as the result. This is the condition with the after-loaded muscle.

But neither of these forms of work is used by the muscles in active life. Therefore, any results or conclusions obtained by them under these conditions would be of limited value. What seems to me to be a better form of work might be explained thus: Let a man lift a weight from the floor to the table and leave it there, reach down and lift another and continue. Work is being performed by him only with the lifting of the weight. During the remainder of the time the muscles are relaxed and resting for the following task. Its cycle in work would be contraction, relaxation without load and rest. The muscles expend little or no energy during relaxation and none at all during the rest period. Fick, by means of his Arbeit-sammler, has applied this method to the frog muscle. Broca and Richet ${ }^{13}$ have made a few experiments on the human muscle. Their work, however, has not been very extensive. Hall ${ }^{14}$ applied this idea of Fick to the human muscle independently of Broca and Richet.

The above criticisms may be summarized as follows:

(1) The various forms of the Mosso ergograph "load" the muscle and cause it to exert energy in some form constantly, while work is being accomplished part of the time only.

(2) The spring ergograph "after-loads" the muscle when used to record isotonic contractions and allows rest for the muscle between relaxation and contraction, but not during relaxation.

\section{METHODS}

With a view of overcoming as many of the objections as possible and applying this method of work to the human muscle, Hall's work-adder was devised. A detailed account of the instrument is necessary, as no description of it has ever been made in literature. By it the muscle works only during the actual lifting of the weight. The troublesome inertia is lessened by having the weight made heavy and having it move so slowly that it follows

13. Broca and Richet: Experiences ergographiques pour mesurer la puissance maximum d'um muscle en régime regulier, Acad. of Sci. Comptes Rendus, 1898 , p. 356.

14. Hall : A New Form of Ergograph, Amer. Jour. of Physiol. vi. append. xxiii. 
the action of the finger very closely. Variations are allowed in the size of the weight by changing the leverage.

The objection may be raised that if the weight is of such large size, the finger, when nearly exhausted, will fail to move it, and there will be no record of the energy spent. But that the muscle may work to the full extent, a heavy weight is necessary. There are two kinds of work: (1) One in which the task is very great for that muscle and requires relatively an immense amount of energy to be expended with every effort put forth. This method can last for a short time only when exhaustion follows and a rest is necessary. (2) The other form is that in which the task is considerably below the working capacity of that muscle, and a relatively smaller amount of energy is put forth. The latter can be continued for a much longer time without fatigue neces-

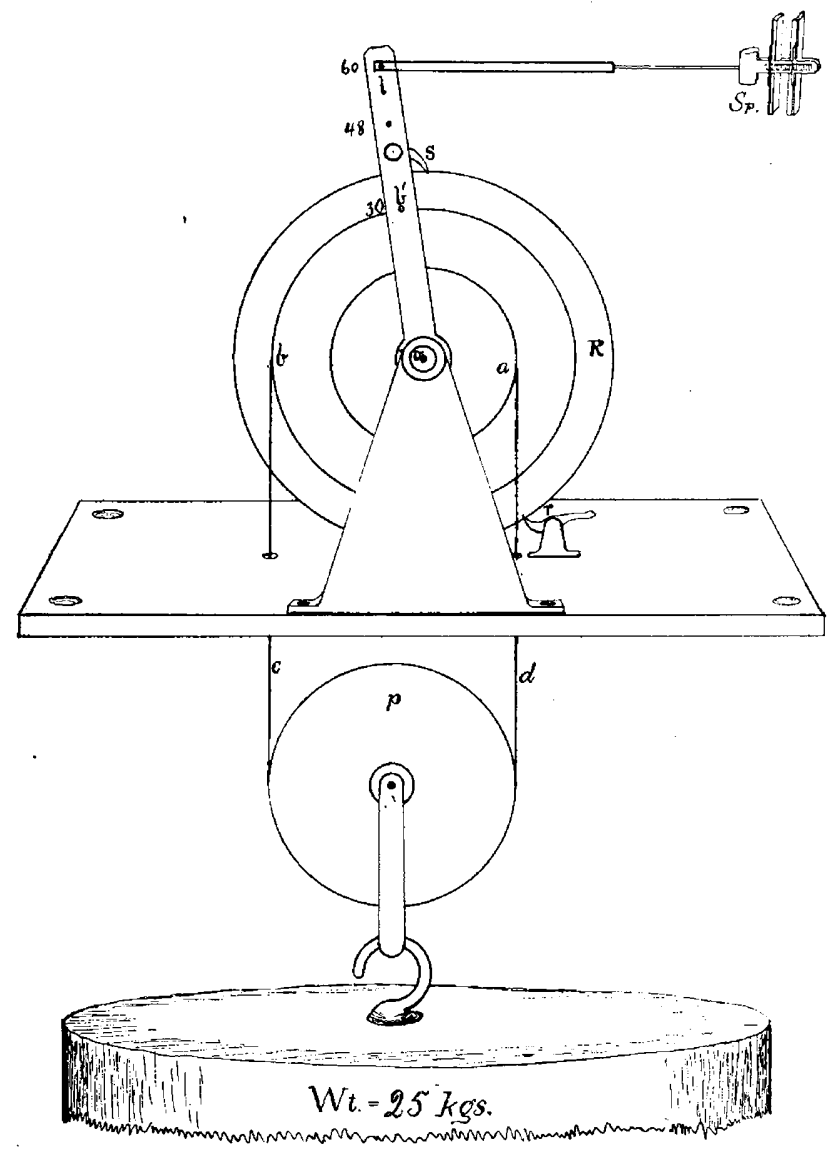

Fig. 1.-Diagram of worik-adder, a, Small drum, $36 \mathrm{~mm}$. in diameter; $b$, large drum, $60 \mathrm{~mm}$, in diameter; $c d$, wire winding off drum a, around pulley $p$, and on to drum $b ; r$, ratchet wheel, fixed immovably to both drums (this wheel has a toothed edge not shown in the figure); sp, finger splint or boot, which clamps the two terminal phalanges of the middle finger; r-s, ratchets ( $r$ fixed and $\mathbf{s}$ movable); 1 , the lifting or pulling lever, here set to lift at $60 \mathrm{~mm}$. from the center o, thus lifting one-tenth of the weight, $25 \mathrm{kgs} .$, as explained in the text. The splint may be attached to the lever at $48 \mathrm{~mm}$. or at $30 \mathrm{~mm}$.; in the latter case the amount lifted by the finger would be $\overline{0} \mathrm{kggs}$, or 11 pounds. Figure is onehalf actual size.

sarily following. Very different results follow the use of these two methods, and the distinction must be recognized when an interpretation of them is to be made. Some have failed to note this difference and considerable confusion has ben the result. The formula-distance times weight-expresses accurately the amount of work a muscle can do if the conditions of the muscle itself and those under which it works are taken into account. Another objection is that the energy expended in starting the weights is greater than that to keep it going. This is true of every task and is not a valid objection if taken of every day work. Every object that a laborer lifts requires a greater expenditure of energy to start it than to keep it going. When the task is too great for him, he gets no credit for his work, but he still has energy sufficient for a task that is within his strength. The same principle should be applied to the individual muscle. Hough ${ }^{15}$ admitted that "the work of our muscle consists for the greater part . . . in a series of liftings of an approximately constant weight and that this weight is far below the maximum for a given muscle," and also says: "It would be a serious mistake to abandon altogether this type of instrument," viz.: wejght ergograph in fatigue experiments.

It is true that the muscle under normal physiologic conditions is neither loaded nor after-loaded, as these terms are usually understood. It is not under a constant tension as when it contracts isotonically; it varies its length, differing from the muscle contracting isometrically. "During normal physiologic conditions a muscle does not contract isotonically, but always with a change of tension." 16 Expressed affirmatively, the working muscle expends energy only while it is lifting the weight; it varies its tension and rests between lifts. I have chosen to call a contraction under these conditions "normotonic."

\section{THE WORK-ADDER.}

One of the ergographs used in these experiments consists of a weight and a movable pulley suspended by a fine wire (Fig. 1). The two ends of this wire are wound in opposite directions on two drums $(a$ and $b$ ) of different sizes. These drums are fixed on the same movable axis $(o)$, and any movement will wind up the wire on one drum while it unwinds from the other. A ratchet $(r)$ prevents any turning except in the direction which winds it on the larger drum, thus raising the weight. A pulling lever $(o l)$ also rotates freely about the same axis $(o)$, and by means of a ratchet $(s)$ revolves the drum in the direction which raises the weight. The pulling lever then returns by the aid of a weak spring, with the finger, to its original position and is ready for the next pull. Complete rest is thus obtained for the muscle while it is not actively pulling. The heavy weight with the drums orercome, to a great extent at least, the inertia. The system of levers reduces the actual weight raised to within the power of the contracting muscle and allows for variation in its size.

The leverages are explained thus, as shown in Figure 1: The small drum (oa) has a radius of $18 \mathrm{~mm}$. and the larger $(o b)$ a radius of $30 \mathrm{~mm}$. Each end of the wire $(c$ and $d)$, wound on these, supports one-half of the weight or $12.5 \mathrm{kgs}$. The drums act as levers of different lengths, and as each is supporting $12.5 \mathrm{kgs}$., the tendency is for the wire around the larger drum to unwind because of the longer weight arm. This movement is prevented by the ratchet $(r)$. The exact amount of downward pressure to balance the $12.5 \mathrm{kgs}$. on $(o a)$ is shown by the proportion, $30: 18:: 12.5: x$, or $7.5 \mathrm{kgs}$. But there is a weight of $12.5 \mathrm{kgs}$. hanging on the lever $(o b)$. Therefore, the ratchet is sustaining the difference between $12.5 \mathrm{kgs}$. and $7.5 \mathrm{kgs}$, or. $5 \mathrm{kgs}$., and before the weight can be raised this must be overcome. To further reduce this weight of $5 \mathrm{kgs}$. the pulling lever is used. The power arm (ol), which may be varied at will, is $60 \mathrm{~mm}$. long, and the weight arm (ob) is $30 \mathrm{~mm}$. long,

15. Cf. pp. 242 to 245 .

16. Schınck and Gruber: Human Physiology, p. 188. 
the proportion being $60: 30:: 5: x$, or $2.5 \mathrm{kgs}$. Then the actual force necessary to raise $25 \mathrm{kgs}$. by this instrument is a force in excess of $2.5 \mathrm{kgs}$. pulling at the distal end of the pulling lever $(l)$.

The arm rest consists of a slanting board modeled at the end to fit the hand. That the middle finger might have free movement, a notch was cut in the board. Straps hold the arm, hand and fingers in place. The first, third and fourth fingers are bent over the end of the rest and held in the partly flexed position by the straps. This allows the contracting muscle to pull the working finger toward the position held by the others instead of away from it and gives an easier movement.

This instrument fulfills the requirement (1) that the muscle works only when pulling the weight upward; (2) that the tension varies; (3) that the inertia be reduced and (4) that the muscle be neither loaded nor afterloaded. But the mechanical construction is at fault since the heavy weight after being raised to a distance of $50 \mathrm{~cm}$. must be lowered again before the work can be continued again, thus allowing a rest for the muscle. Therefore, while it is suitable for ordinary fatigue work, it is not adapted to recording continuous efforts. That the experiments might continue with the same idea in view, another instrument of different mechanical construction, but involving the same principles, was made and substituted. Its construction and methods of work will be given.

\section{THE AIR CUSHION.}

The essentials of this instrument consist in an upright cylinder (see Fig. 2, c) closed at the lower end except for a large inlet valve $(a)$ and at the upper end by a very thin sheet of dentist's rubber dam loosely stretched across it. A stopcock $(b)$ is placed in one side of the cylinder. The weight while resting on the rubber sheet is not supported by it, but by a small metal bar (d) which strikes the frame. The action is as follows: As the weight is lifted from the cushion, air rushes in through the valve $(a)$. When it is lowered, it strikes the rubber sheet and causes an increase of pressure within. This compressed air acts as a support until its slow escape through the stopcock $(b)$ allows a return of the normal pressure within and the weight to be lowered, until it is caught by the metal bar. The rapidity with which it is lowered is regulated by the size of the opening made by turning the stopcock.

A wire extends from the weight up to an elbow lever (l) fixed at the end of the arm rest, and another extends horizontally from this to the finger where it is attached by an adjustable metal splint or boot $(s p)$. The tracing lever records the actual movement of the finger on the drum $(D)$. The size of the weight is easily changed by varying the length of the two arms of the elbow lever. The arm rest used was similar to the one described with the work-adder.

\section{A PACE FOR THE WORKING MUSCLE.}

In previous ergographic work much attention has been paid to the character of the individual tracing and to the production of fatigue. In general, not over one hundred contractions were necessary to bring on this fatigue. But very little study has been made to ascertain under what conditions a muscle can continue to work for a long period of time. In 1890, Maggiora ${ }^{2}$ found that he could contract the middle finger of his left hand continuously at the rate of one contraction in two seconds against a weight of $1 \mathrm{~kg}$. He concluded from his experiments that there exists for the human muscle a definite weight with which one can perform the greatest possible work. When the weight or the rate of contraction is increased, fatigue will occur. He also found that this maximum of work varies with different persons at the same time and the same muscle at different times. Lombard ${ }^{3}$ contracted the abductor indicis muscle about 9,000 times, or for two and onehalf hours, at the rate of once a second against a weight of 500 gms., reaching about the same conclusions as Maggiora. Both of these investigators used the weight ergograph which loaded the muscle and did not allow the muscle to work to the greatest advantage. Maggiora flexed the entire finger while the hand was in the supine position. Neither seems to have tried to compute the amount of work done by these muscles.

Fick $^{17}$ found that, using a heary weight, about onefourth of the total energy expended by a muscle is used in lifting it and the remainder is changed into heat, electricity, etc.; while with a light weight, only about

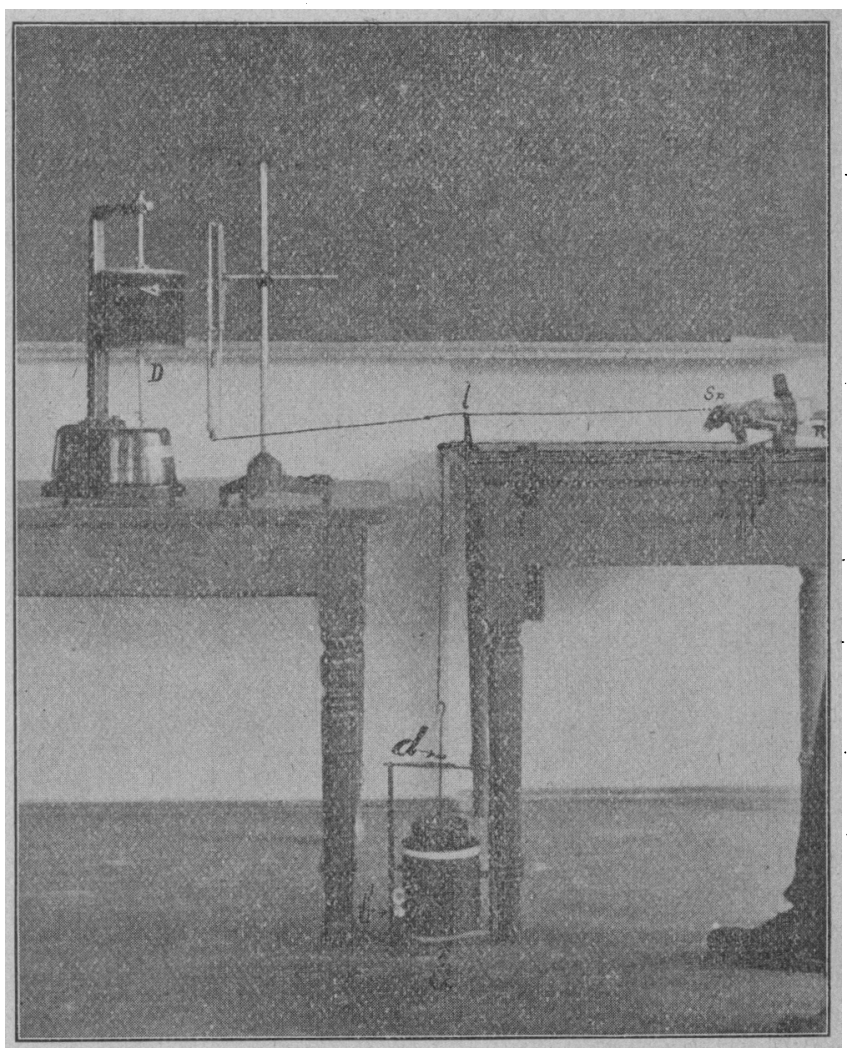

Fig. 2.-Ergograph with alr-cushion. C, cylinder, about $10 \mathrm{~cm}$. in diameter, having a large valve (a) opening from below; $b$, stopcock through which the alr escapes on descent of the weight, the rate at which it escapes is regulated by the stopcock; $d$, metal bar soldered to the weight rod, this bar strikes the cylinder frame and serves to support the welght between contractions; l, elbow lever, so. constructed that the two arms may be varied in length by hooking the weight cord or the power cord into different holes; Sp, finger splint; $R$, arm rest; $D$, drum of kymograph.

one-twentieth is spent as external work. That there is so much loss of energy is due, I think, to the fact that the muscle does not work to the greatest advantage. While some attempts have been made to improve the condition under which the muscle works, sufficient data have not been tabulated to show the true value of these changes.

The results given here were obtained principally on the air cushion. That the muscle might be in training, as Hough ${ }^{18}$ has shown is necessary for the best results,

17. Fick: Pfluger's Archives, 1878, xvi, p. 85 .

18. Hough : Ergographlc Studies in Muscular Soreness, Amer. Jour. of Physiol., 1902, vil, p. 76. 
the experiments were continued over a period of two months in the spring of 1902 and about three months in the spring of 1903. Tracings were made at least every other day. While the experiment was being made, the subject sat at a table with the right arm and hand fastened in a prone position to the rest. Different weights were used, the rule being to increase them as the finger becomes accustomed to the work. At first the muscle became tired very quickly, but after a few weeks it gained in power and could use the heavier weights at a faster rate of contraction. The rhythm was usually a matter of choice and was influenced largely by the object in view. While many found that they could bring on fatigue within one-hundred contractions at the rate of one contraction every two seconds, I found that I could go at a much faster rate and continue a very much longer time without fatigue necessarily following. The height of the contractions remained practically the same, varying from $1 \mathrm{~cm}$. to $1.5 \mathrm{~cm}$. in height. Throughout the experiments care was taken to keep the nutrition of the finger and muscle as nearly normal as possible. No attempt was made to compute the friction, which was comparatively small. Tension on the muscle was present only during the lifting of the weight.

The following table shows some of the results obtained:

TABLE 1

\begin{tabular}{|c|c|c|c|c|c|c|c|}
\hline Date. & 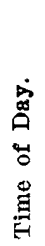 & 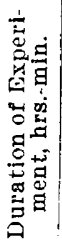 & 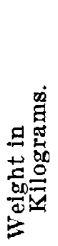 & 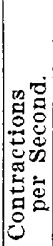 & 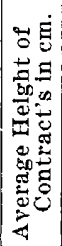 & 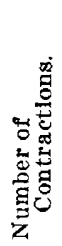 & 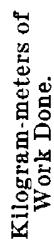 \\
\hline
\end{tabular}

A.-Results Obtained on the Work-adder re Sprixg of 1902. May 8, $1902 \ldots \ldots \mid 8: 12$ a. m. $|3: 47| 2.5|1| 2.2|11.370| * 625.35$

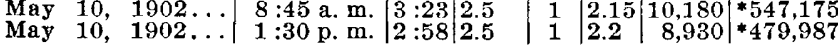
B.-Results Obtained on Air-cusfion in Spring of 1903.

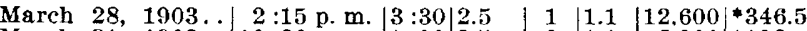

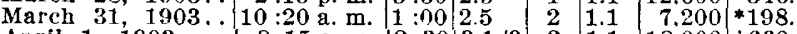

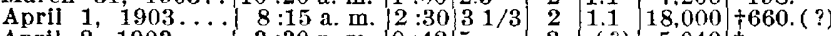

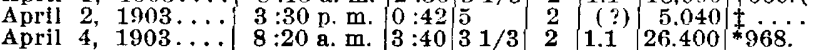
* No fatigue. + Some irregularity. \$Tracing irregular after 9 minutes; fatigue in 42 minutes.

Part A of Table 1 shows the results of the experiments on the work-adder. The longest single experiment was made May 8, and lasted for a period of three hours and forty-seven minutes, during which time over 11,000 contractions were made, and about 625 kilogram-meters of work accomplished. May 10 two tests were made with an interval of one hour and thirty minutes. The work done that day amounted to over 1,000 kilogrammeters. No fatigue other than a general body weariness was experienced after these experiments, and the height of the contraction remained very constant throughout each experiment. But the experiments were not above criticism, as there was some movement of the whole finger, and intervals of rest were made necessary when the weight was lowered.

Part $B$ of Table 1 shows the work accomplished on the air cushion. March 28 I made 12,600 contractions in three and one-half hours. The rate was one contraction every second against a weight of two and one-half kgs. The average height of each of the tracings was 1.1 $\mathrm{cm}$. and the total work accomplished 346.5 kilogrammeters. No fatigue occurred. On April 1, the rate of contractions was changed to 2 per second and the weight to $31 / 3 \mathrm{kgs}$. It was thought that this would bring fatigue; but to my surprise, after some irregularity in the tracing, the height of the contractions became more even and no fatigue was produced in two and one-half hours. The next tracing was made at the rate of two contractions a second with a 5-kg. weight. The tracing was regular for nine minutes, then varied considerably in height until fatigue (a failure to move the weight) came on at the end of forty-two minutes.

On April 4 the weight was changed back to $31 / 3$ kgs., and with the same rate 26,400 contractions were made in three hours and forty minutes. The contractions varied between 1 and $1.4 \mathrm{~cm}$., with an average of about $1.1 \mathrm{~cm}$. Not over twenty-five strokes were lost during the entire time, and the wide variations to be expected from weariness or disturbances were surprisingly absent. No fatigue occurred except a general weariness of the whole body, which lasted during the remainder of the day. The weariness did not stop the work of the experiment, however. The total amount of work was over 968 kilogram-meters.

Comparing this last tracing with that of April 2, it will be seen that the heaviest weight that this muscle can lift continuously, contracting twice a second, is between $31 / 3$ and $5 \mathrm{kgs}$. No similar amount of work has, to my knowledge, been recorded previously by a single muscle. This apparent increase of ability must be due, in a great measure, to the more advantageous conditions under which the muscle is working. Just how long this work could have continued I will not venture to say definitely, but the fact that I could keep up this pace for three hours and forty minutes without fatigue of the muscle following would justify the conclusion that the muscle could have done more. It is evident in the above experiment that the muscle had sufficient rest after each contraction to recover from the effects of that contraction. Had this not been the case fatigue would have been the result, as it had been with the use of the $\tilde{5}-\mathrm{kg}$. weight.

Since so many factors enter in to modify the conditions, it is not to be expected that the results will be the same in each experiment; but with the conditions sufficiently favorable it may be concluded that a muscle is able to do a day's work of eight or ten hours' duration.

\section{FATIGUE.}

Mosso, ${ }^{1}$ Lombard, ${ }^{3}$ Maggiora ${ }^{2}$ and others found that the muscle became tired and could not lift a given weight after from 50 to 100 contractions, the rate being once a second. With them, the amount of work, as well as the extent of movement, decreased as fatigue was approached. Franz ${ }^{19}$ found that with the spring he could contract 150 times and still do about 40 per cent. as much work as at the beginning of the series. During the present experiments the muscle was fatigued several times and it always gave results far in excess of those obtained by these men. The muscle did not become fatigued within a period of three hours and forty minutes when it raised a $31 / 3-\mathrm{kg}$. weight twice a second. On April 2 the muscle became fatigued in forty-two minutes after having made over 5,000 contractions against a $5-\mathrm{kg}$. weight, lifting it twice a second. After a lapse of about four weeks, it made nearly 4,000 contractions under the same conditions.

That I might find a cause for this great difference in ability, I made a few experiments with the Mosso form of ergograph. Table 2 shows some of the results as compared with those taken with the air cushion: 
TABLE 2.

\begin{tabular}{|c|c|c|c|c|c|c|}
\hline & $\begin{array}{l}\text { Date. } \\
1903 .\end{array}$ & 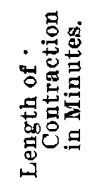 & 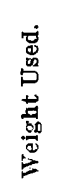 & 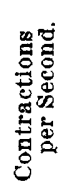 & 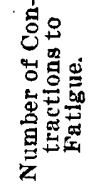 & 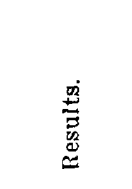 \\
\hline \multicolumn{7}{|c|}{ RESULTS WITH AIR-CUSHION. } \\
\hline $\begin{array}{l}\text { April } \\
\text { April } \\
\text { April }\end{array}$ & $\begin{array}{lll}2 & \ldots & \ldots \\
4 & \ldots & \ldots \\
29 & \ldots & \ldots\end{array}$ & $\begin{array}{r}42 \\
220 \\
33\end{array}$ & $\begin{array}{l}5 \\
3 \\
5\end{array} 1 / 3$ & $\begin{array}{l}2 \\
2 \\
2\end{array}$ & $\begin{array}{r}5,040 \\
26,400 \\
3,960\end{array}$ & $\begin{array}{l}\text { fatigue } \\
\text { no fatigue } \\
\text { fatigue }\end{array}$ \\
\hline \multicolumn{7}{|c|}{ RESULTS WITHODT AIR-CUSHION. } \\
\hline $\begin{array}{l}\text { April } \\
\text { April } \\
\text { April }\end{array}$ & 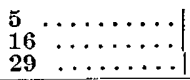 & $\begin{array}{l}22 \\
24 \\
\quad 1: 08\end{array}$ & $\begin{array}{l}31 / 3 \\
31 / 3 \\
5\end{array}$ & $\begin{array}{l}2 \\
2 \\
2 \\
\end{array}$ & $\begin{array}{r}2,640 \\
2,880 \\
\quad 135 \\
\end{array}$ & $\begin{array}{l}\text { fatigue } \\
\text { fatigue } \\
\text { fatigue }\end{array}$ \\
\hline
\end{tabular}

These tracings compare the time and work necessary to produce fatigue when the air cushion is used and without it.

These results do not agree with those obtained by the previous investigators. With a weight of $31 / 3 \mathrm{kgs}$. twice a second, there was no fatigue until 2,640 , and in another 2,880, contractions had been made. At another time the muscle, contracting every half second, raised a weight of $5 \mathrm{kgs}$. 135 times before fatigue was produced.

The question arises, why there should be such a difference in the amount of work necessary to produce fatigue? The individual variations of the muscles would easily explain small differences, but would not suffice here. The muscle that I used was below the average in strength before the experiments began, and the time over which the experiments extended would scarcely allow such great increase in power. The difference which exists between the tracings made with the air cushion and those with the Mosso form of ergograph can be explained to a great extent by the conditions under which the muscle was working. The other is evidently the result of the endurance which the muscle gained by working many times over an extended period.

\section{RECOVERY AFTER FATIGUE.}

It was also noticed that the periods of recovery after fatigue had been reached were very much longer when the air cushion was used, than when the Mosso form of ergograph was used. The average number of contractions in the recoveries of an experiment lasting one hour and forty minutes was eighty-five, and the average intervals of absolute fatigue was fifty seconds, varying in length from 2 to $10 \mathrm{~cm}$. 'The weight used was $5 \mathrm{kgs}$, raised every one-half second. There was no regularity in the length of the recoveries, while the intervals of loss of power had a tendency to become longer as the experiment was continued. For a detailed discussion of this subject the reader is referred to the work of Lombard. ${ }^{20}$

\section{SUMLMARY.}

1. A muscle working under normal physiologic conditions is neither "loaded" nor "after-loaded."

2. A muscle will not contract isotonically nor isometrically under normal physiologic conditions.

3. When a Mosso or a spring ergograph is used, a large part of the energy expended by a muscle during a period of work is lost. This loss occurs in easing back the weight or the spring to its position of rest or to the zero point.

4. A recognition of the conditions under which a muscle works and the end to be attained is necessary

\footnotetext{
20. Lombard: The Effect of Fatigue on Voluntary Muscular Contractions, Jour. of Psychol, 1890, vol. iil.
}

when an interpretation of ergographic results is to be made.

5. A normal muscular contraction ("normotonic") consists in contraction, relaxation without load, rest.

6. A new form of weight ergograph has been devised which allows the human muscle to work at a greater advantage than that given by any previous form of ergograph, because it permits "normotonic" contractions.

7. A human muscle is capable of doing a far greater amount of work by the use of the new ergograph than has been previously shown in ergographic work.

8. A muscle can work over periods of long duration without fatigue when the conditions are favorable.

9. These experiments confirm the conclusion stated by Maggiora that there is a definite weight with which one can perform the greatest possible work.

10. The physiologic limit of a muscle for continuous work is modified by the rate, load and interval, or by rest and work.

\section{DYSTOCIA CAUSED BY DOUBLE CONGENITAL CYSTIC KIDNEYS IN THE NEW-BORN:}

\section{A CONTRIBUTION TO THE STUDY OF CONGENITAL CYSTIC} KIDNEY.

EDWARD E. MORSE, M.D., L.M. (DUBLIN).

Demonstrator of Obstetrics, Columbian University; Associate Visiting Surgeon Columbian Hospital for Women; Associate Obstetrician University Hospital. WASHINGTON, D. C.

Spiegelberg, in his well-known "Midwifery," vol. ii, p. 169, speaking of the causes of difficult labor produced by anomalies of the fetus and appendages, says: "The various causes which lead to the enlargement of the abdomen of the fetus are the following:

"1. An accumulation of serum.

"2. The distention of the urinary organs with urine, both bladder and uretus.

"3. Cystic degeneration of the kidneys.

"4. Distention of the uterus with fluid.

"5. Tumors of the liver, spleen, testicle in the abdomen.

"6. Aneurism of the aorta.

"\%. A condition in which one fetus is included in another."

Under the third of these headings, viz., cystic degeneration of the kidneys, I wish to report a case of dystocia which recently occurred in my practice:

ivrs. X., aged 20, primipara, healthy, and pelvis normal, came into labor early in the morning of January 19. In the beginning the pains were of normal character and continued increasing in strength and frequency during the day and evening. Dilatation of the os was very slow. A breech presentation was easily diagnosed. The pain steadily increasing and becoming progressively harder and the os not opening proportionately, it was decided at $11 \mathrm{p} . \mathrm{m}$. to anesthetize and deliver. Under ether there was no difficulty in dilating sufficiently to admit several fingers and grasp the feet. Traction brought the limbs well through the os, but the abdomen resisted all efforts. An examination cautiously made demonstrated some obstruction of a very considerable character in the abdomen, which was felt to be enormously swollen. By repeated and persistent traction, combined with careful manipulation, the trunk and after-coming head were eventually born, without resorting to any cutting or destructive operation. When born the child breathed a few times, not, however, emitting any cry, but very shortly breathing ceased.

The uterus contracted firmly after the discharge of a small quantity of blood, very dark in appearance. The recovery of the mother was uneventful. The conditions surrounding 